\title{
Does Equity Derivatives Trading Affect the Systematic Risk of the Underlying Stocks in an Emerging Market: Evidence from Pakistan's Futures Market
}

\author{
Safi Ullah Khan* and Zaheer Abbas**
}

\begin{abstract}
This paper examines the behavior of beta coefficients (systematic risk) for underlying stocks around the introduction of single-stock futures (SSFs) contracts in the Pakistani market, by employing models that account for nonsynchronous and thin trading and varying market conditions as "bull" and "bear" markets. Unlike the results of earlier studies on US markets, the empirical evidence tends to support a decline in systematic risk for the majority of underlying stocks in the post-futures listings period. Nevertheless, similar to SSFs stocks, we also find empirical evidence of a decrease in systematic risk for many of the control group stocks. This indicates that changes in beta estimates for SSFs-listed stocks might not be induced by the introduction of SSFs contract trading, but could be attributed to other market-wide or industry changes that have affected the overall market. Several plausible reasons, such as lack of program trading activities normally associated with index futures, market microstructure differences between developed markets and a developing market such as Pakistan, and the capturing of the "bear" and "bull" market effects on stock betas in our estimation procedure could explain these different results for Pakistan's market.
\end{abstract}

Keywords: Systematic risk, beta, stock index futures, single-stock futures, stock price volatility, GARCH model, bear and bull markets, thin trading, Pakistan.

JEL classification: G10, G13.

\section{Introduction}

Single-stock futures (SSFs) are futures contracts written on individual shares (underlying assets), and were first introduced on the Australian market in 1996. Many markets have since made them available

\footnotetext{
* Institute of Management Sciences Kohat University of Science and Technology, Khyber Pakhtunkhwa, Pakistan.

${ }^{* * *}$ Faculty of Management Sciences, International Islamic University, Islamabad, Pakistan.
} 
to investors and many more are contemplating introducing SSFs. ${ }^{1}$ Though the effect of stock index futures trading on the price volatility of the underlying assets has been widely examined in finance literature, SSFs, being newer derivatives products, have not received much attention-in particular, their effect in emerging markets. ${ }^{2}$ While SSFs are a useful addition to the range of instruments available to investors, providing a better match for investment and risk management purposes than the broad-based stock index futures, concerns about their impact on the underlying assets remain.

This paper examines one relatively neglected aspect of SSFs trading in the literature-the possible relationship between $\mathrm{SSFs}^{3}$ contracts trading and the behavior of the systematic risks ${ }^{4}$ of underlying stocks in Pakistan's equity market. The study contributes to the literature on the SSFs market in several ways. First, it extends the literature on SSFs to a market that has not yet been studied to examine SSFs trading in relation to the sensitivity of the underlying assets. Despite the fact that SSFs were introduced onto Pakistan's market much earlier than in many markets around the world, including the US market, 5 researchers have largely ignored the Pakistani market in this context. Two key exceptions are Khan (2006) and Khan and Hijazi (2009), who examine the relationship between SSFs trading and the price volatility of the underlying stocks in the Pakistani market, and report that SSFs trading has some soothing effect on the underlying stocks' level of volatility. Nonetheless, this market has not, by and large, captured researchers' attention. We attempt to fill this gap.

Moreover, though academic interest in SSFs trading and the underlying market is growing and a number of studies have examined the price and volatility dynamics of SSFs trading, to the best of our knowledge none have looked at SSFs trading and the beta relationships of the underlying stocks. Our paper aims to trigger further research on this topic.

Additionally, because of their unique characteristics, a study of SSFs contracts offers several advantages over the study of broad-based

\footnotetext{
${ }^{1}$ Presently, SSFs are available in Australia, the US, UK, South Africa, India, Malaysia, Hong Kong, and certain other markets.

${ }^{2}$ Studies by Vipul (2008) and Dawson (2007) are exceptions.

${ }^{3}$ SSFs are known as deliverable futures contracts (DFCs) in Pakistan, probably because of their physical settlement by delivery of the underlying shares. Cash-settled SSFs contracts are also available in some markets (for instance, in India).

${ }^{4}$ Systematic risk is a covariance of an asset's returns with that of market returns and is statistically measured by beta.

${ }^{5}$ It may be pertinent to mention that trading in SSFs in the US market was discontinued in the 1980s due to matters of regulatory jurisdiction and only allowed in 2003.
} 
index futures contracts. First, the effect of index futures on the underlying asset may not be measured as accurately as the effect dissipates across many constituent stocks, whereas trading in SSFs-underlying stocks can be directly observed in the spot market, making it easier to accurately measure SSFs-related effects. Second, multiple introduction dates for SSFs mitigate the limitations of single-event studies of index futures, and help to evaluate their effect on underlying assets in different time periods. Hence, any impact of derivatives is likely to be more evident in the behavior of individual stocks than in an overall index returns.

Our empirical results are summarized as follows. We observe a significant decrease in beta estimates for many of the SSFs-listed stocks in the post-futures trading period. Nevertheless, a considerable number of control stocks also behave in a similar fashion. The results thus fail to reject the hypothesis that SSFs trading might not have an impact on the systematic risk of the SSFs-listed stocks, either in the short or long run. The next section reviews the theoretical and empirical literature, followed by a description of the data and methodology. The last section concludes the paper.

\section{Literature Review}

\subsection{Theoretical Background}

No specific theories or models have been presented to explain why there should be any relationship between equity derivatives trading activities and the systematic risk or co-movements between individual securities and market returns. Nevertheless, two hypotheses are put forward as a possible explanation for the relationship between trading activities associated with stock index futures trading-such as program trading and portfolio insurance activities by large institutional investors-and the responsiveness of individual securities returns to market or index movements.

The first is the "price pressure hypothesis"6 (Shleifer, 1986; Harris \& Gurel, 1986), which finds widespread application in the literature on the inclusion of a stock in an index and the consequent short-term

\footnotetext{
${ }^{6}$ This theory has been tested in a variety of markets and in a number of settings in an attempt to explain price reactions/effects, such as an increase in stock return volatility and trading volumes, to different events such as stock additions to or deletions from an index. See, for example, Shleifer (1986), Dhillon and Johnson (1991), and Elliot and Warr (2003) for the S\&P 500 index; Brealey (2000) for the UK market; Chan and Howard (2002) for the Australian market; Trahan and Bolster (1997) and Keral and Walter (2006) for analyst buy recommendations; and Sias, Titman, and Starks (2001) for the price impact of institutional trading.
} 
uncharacteristic increase in stock price volatility and trading volumes. After the inclusion (exclusion) of a stock in an index, there is a temporary rise (fall) in demand for the stock over a short period because of heavy trading caused by the rebalancing of the index tracking funds. Once these abnormal trading activities return to normal levels, the prices revert to and reflect the equilibrium levels, exhibiting a temporary increase in the trading volumes and variance of returns. Generalizing this to an index arbitrage and program trading activities, large institutional investors seeking to exploit arbitrage opportunities - in case a stock index futures price is higher (lower) than the value of the index itself-sell (buy) the futures and buy (sell) the underlying stocks, typically in a "basket" of stocks worth millions of dollars. Thus, one would find a portfolio of stocks reacting in a similar fashion, and this may lead to an increase in their degree of co-movement.

The second hypothesis that could explain the effect of program trading on stock returns is the "cascade theory", which posits that program selling aggravates declines in stock prices. Portfolio insurers typically carry out portfolio insurance adjustment strategies for large "baskets of stocks" by trading in index futures because of the lower transaction costs in the futures market compared to the cash market. They sell index futures rather than the underlying basket of stocks to hedge against market risk, leading to a decrease in the futures prices relative to the spot market value of the index. This decline in index futures relative to spot market prices induces index arbitragers to enter the fray and purchase futures, selling the underlying stocks. Thus, index arbitrage transmits to the cash market the portfolio insurers' selling pressure in the futures market, which causes further declines in cash market prices. This triggers further selling in futures by the portfolio insurers, which is again transmitted to the stock market by the arbitragers and so on, causing "downward cascading" in stock prices.

\subsection{Empirical Evidence}

The empirical literature on the effect of derivatives trading on the systematic risk factors of underlying stocks is scarce, and often presents conflicting results. For instance, Skinner (1989) reports that, with the initiation of the options on stocks, the return volatility decreases while the beta is unaffected; Conrad (1989) gives similar results. In contrast, Martin and Senchack (1989) use monthly returns for stocks composed of the major market index (MMI) by employing an event study (before and after) methodology, and report an increase in the systematic risk for 20

MMI stocks after the introduction of MMI futures. They attribute this to 
the use of controversial techniques such as program trading ${ }^{7}$ by investors in the US market.

Applying a more sound methodology than their earlier study, Martin and Senchack (1991) use daily returns data on MMI-constituent stocks and compare changes in the stock's percentage systematic risk with a control sample of 20 stocks that do not belong to an index with a traded futures/options contract. The results indicate an average increase in percentage systematic risk for the $20 \mathrm{MMI}$ stocks. The nonindex stocks show little evidence of increased systematic risk. The study also reports an increase in average correlation between index stocks, which they do not find for nonindex stocks. These findings lead the authors to conclude that the increase in systematic risk for index stocks can be attributed to the program trading in the index stocks associated with the index futures contracts. Similar results are also reported by Vijh (1994) with significant increases in beta estimates for Standard and Poor's (S\&P) 500 stocks relative to the nonindex stocks, which the author attributes in part to the price pressures or excess volatility caused by the S\&P 500 trading strategies, which also include program trading activities.

Other studies, however, find no evidence of changes in the beta coefficients of the underlying index-constituent stocks. Galloway and Miller (1997) examine the effect of MidCap index futures trading on the changes in the systematic risk for stocks comprising the index and two control samples that consist of medium- and large-capitalization stocks. They use both OLS betas and those that are adjusted to account for nonsynchronous trading that might cause bias in the beta estimates, with various lead/lag structures. The study reports a significant decrease in beta estimates for samples of medium- and large-capitalization stocks while no such change is found for the component stocks in the MidCap index futures. These findings lead them to infer that trading in index futures has no effect on the systematic risk, beta coefficient, of the index stocks.

Kan and Tang (1999) analyze Hang Seng Index (HSI) (Hong Kong) futures-constituent stocks, applying a "varying risk market model" to daily stock return data in the context of the pre-versus-post-HSI futures period. They find no evidence of an increase in the systematic risk of HSI-

\footnotetext{
${ }^{7}$ Program trading strategies are generated trading strategies that involve the simultaneous sale and/or purchase of a large basket of securities, and are used primarily for index arbitrage, market timing, and portfolio insurance. Though program trading can occur in different ways, the most widely known strategy is index arbitraging, which, as Martin and Senchack (1989) propose, "involves purchasing (selling) the cash stock portfolio and simultaneously selling (purchasing) the index futures contract when the futures price exceeds (is less than) the spot price of the index, net of the cost carry.”
} 
constituent stocks in the post-futures trading period either in the short or long run. Since then, few studies have focused on this issue, though much has been written on the volatility effects of futures trading.

Numerous empirical studies have found that beta estimates can be biased because of nonsynchronous trading and market frictions such as thin trading, trading delays, and price adjustment delays. This can cause the beta estimate to be biased toward zero-the bias is known as the "Epps Effect" (Epps, 1979) and is reported in Dimson (1979) and Hayashi and Yoshida (2005). The phenomenon of nonsynchronous trading occurs primarily in markets characterized by thin trading as closing prices are recorded at the close of the session. These prices can reflect transactions that had occurred well before the close of the session for many stocks. Iqbal and Brooks (2007) acknowledge and document the infrequent trading characterizing the Karachi Stock Exchange, and accordingly adopt Dimson's (1979) technique to correct the bias in their beta estimations.

\section{The SSFs Market in Pakistan}

SSFs were introduced on the Karachi Stock Exchange (KSE) - the largest of Pakistan's three exchanges-on 1 July 2001. Initially, nine stocks were selected for SSFs contracts listed on the exchange. The number of SSFs contracts were increased in phases to a total of 46 stocks by February 2008. Overall, these 46 contracts provide market coverage to each of the major sectors of Pakistan's economy: commercial banks (17 SSFs), textiles (one SSF), cement (five SSFs), power generation and distribution (three SSFs), oil and gas marketing (three SSFs), oil and gas exploration (three SSFs), synthetics and rayon (two SSFs), transport (one SSF), technology and communication (two SSFs), refineries (four SSFs), insurance (one SSF), and fertilizers (three SSFs).

Trading in SSFs takes place through the computerized Karachi Automated Trading System and is displayed on KSE's market information system. SSFs contracts are available on a one-calendar-month expiry cycle, ${ }^{8}$ with the last Friday of the month as the last trading day in a contract, and are settled on the following Wednesday through a KSE clearinghouse as there is no separate, independent futures exchange for SSFs trading in Pakistan. SSFs contracts are settled through the physical delivery of shares on the expiration

\footnotetext{
${ }^{8}$ Recently, the KSE introduced 90-day, cash-settled SSFs in a few scrips. These were initially introduced in only three stocks, but the KSE plans to gradually increase them to other stocks. The KSE has only recently introduced stock index futures with the KSE-30 index as the underlying asset. The introduction of all these different types of equity derivatives does not coincide with our sample time period in order to avoid confounding our empirical results.
} 
of the contract since there is no option for cash settlement, and final holder of the futures contract has to take delivery of the underlying stocks. ${ }^{9}$

Contracts for different months can trade on the exchange at the same time. There is an overlapping period for contracts: the period for the new contract can start at least two trading days before the close of the old one. A circuit breaker is put in place if there is a price fluctuation of 7.5 percent or PKR 1.5, whichever is higher, compared to the previous day's closing price. The Annex summarizes the salient contract specifications of SSFs contracts traded on the KSE.

\section{Varying-Risk Market Model for Evaluation of Risk Estimates}

In order to examine changes in beta for SSFs-listed stocks-as modeled by the capital asset pricing model (CAPM)-after the introduction of SSFs contracts for those stocks, we estimate pre-event and post-event betas for each stock. Earlier empirical applications of the CAPM and studies such as Rowe and Kim (2010), Yip and Lai (2009), and Frimpong (2010) have used the market model approach, which assumes a constant beta. Numerous studies show that systematic risk varies over time, with different variables describing the financial structure (see, for example, Ulosoy, 2008; Rowe \& Kim, 2010; Patton \& Verado, 2009) or the business cycle (see Shanken, 1990; Ferson \& Schadt, 1996).

Some studies have documented changes in beta estimates for individual stocks under varying market conditions, i.e., "bull" and "bear" markets. Fabozzi and Francis (1977, 1979), for instance, report varying beta and alpha estimates for stocks in bull and bear markets. Francis and Fabozzi (1979) and Jagannathan and Wang (1996) also report similar results. Howton and Peterson (1998) document the relationship between beta and stock returns that changes in bull and bear markets even after controlling for other determinants of stock returns such as size, book-tomarket ratio, and earnings-price ratio. Their findings highlight the importance of using a varying-risk model to estimate stock betas.

Damodaran (1990) employs daily returns data to compare beta changes for S\&P 500-constituent stocks and nonindex firms, and finds, on average, higher betas for S\&P 500 index stocks in the post-futures period compared to nonindex stocks, which reveal, on average, no change in betas. Even after accounting for firm-specific fundamental (accounting) variables (such as dividend yields, D/E ratio, book value of assets, and

\footnotetext{
${ }^{9}$ Physical settlement is implemented in both One Chicago and NQLX exchanges in the US market, in contrast to cash settlement in LIFFE Universal Stock Futures contracts (UK).
} 
cash-to-total assets), the author concludes that this increase in beta could be related to trading activity variables, which show much more trading and noise subsequent to the index futures trading.

In light of the discussion above and the methodologies used by previous studies to account for varying market conditions, we employ a varying-risk market model to control for the possible differential return premiums between bull and bear markets. Following Kan and Tang (1999), we adopt the following varying-risk market model to examine SSFs trading and systematic risks effects:

$R_{i, t}=\varphi_{1}+\varphi_{2} D_{1}+\varphi_{3} D_{2}+\varphi_{4} D_{1} D_{2}+\beta_{0} R_{m, t}+\beta_{1} D_{1} R_{m, t}+\beta_{2} D_{2} R_{m, t}+\beta_{3} D_{1} D_{2} R_{m, t}+\varepsilon_{i, t}$

EMBED Equation.3 $R_{i, t}$ are the weekly returns on a stock $i$ for week $t$ $t-i \times 100-$. The risk-free rate is the annualized 90-day government $\mathrm{t}$-bill rate and is adjusted on a weekly basis. $R_{m, t}$ is the return on the KSE-100 index, taken as a proxy for overall market returns; the excess returns on the market portfolio are calculated in a similar fashion. $D_{1}$ and $D_{2}$ are dummy variables, where $D_{1}$ is equal to 1 in the post-SSFs period and 0 in the preSSFs period, while $D_{2}$ is equal to 1 in bear months and 0 in bull months in either the post-futures or pre-futures period.

The model also allows slope dummies to vary in the post-SSFs period. The product of $D_{1}$ and $D_{2}$ is, therefore, incorporated in the equation to account for the possibility that the "bull and bear market" effects on the stock beta can be influenced by the initiation of SSFs trading.

In equation (1) when $D_{1}=1$, the beta coefficient is $\beta_{0}+\beta_{1}+\beta_{2} D_{2}+\beta_{3} D_{2}$; when $D_{1}=0$, it is $\beta_{0}+\beta_{2} D_{2}$. Therefore, the change in the beta coefficient for a particular stock in the pre-SSFs and post-SSFs period is $\beta+\beta_{3} D_{2}$. The statistical significance of $\beta+\beta_{3} D_{2}$ indicates whether the beta of a stock has changed after SSFs trading has been introduced. If the $\beta_{3}$ coefficient turns out to be statistically insignificant, $\beta_{1}$ may be used to measure changes in the stock's beta in the post-futures period.

There are several definitions of bear and bull markets in the literature. In this study, each month of the sampling interval is categorized as a bull month (with positive rates of return) or a bear month (with negative rates of return), using the definition given by Kan and Tang (1999). This definition is similar to Fabozzi and Francis's (1979) definition of "up and down markets". 


\section{Data Description and Empirical Results: Varying-Risk Market Model}

The data we have used consists of the weekly closing prices of SSFs-listed stocks and a sample of matching non-SSFs stocks for a ten-year period from 1 July 1999 to 31 December 2009. For each SSFs contract, we consider two years' data for the pre-SSFs period and two years' data for the post-SSFs period. The weekly price data is taken as the closing price on Wednesday of each week to avoid any day-of-the-week or weekend effects. We include all 46 SSFs stocks listed on the KSE in our sample. The sample interval for each stock is divided into two sub-periods, i.e., the pre-SSFs period and post-SSFs period, and each sub-period consists of two years' data for each stock during the sample period.

In an attempt to determine whether the changes, if any, in the betas of the SSFs-listed stocks can be attributed to the introduction of futures contracts or whether they are the result of general market or industryspecific changes, we also include a control sample of non-SSFs stocks. NonSSFs stocks are selected from all the major sectors of the economy to ensure that the market is fairly represented. A total of 88 stocks are included in the control group, which, together, comprise about 80 percent of the market's capitalization and represent 18 sectors of the economy. We use the KSE-100 index, a market capitalization-weighted index, to proxy for market returns, and the closing values of the index on the Wednesday of each week to calculate weekly index returns. The index values are adjusted for dividends. The KSE is benchmarked by the KSE-100 index, which represents more than 80 percent of the market's capitalization.

Changes in betas may reflect microstructure price effects or merely changes in true betas. We investigate this issue by examining measured betas over short- and long-window intervals around SSFs listings. We expect true betas to depend on the riskiness inherent in firms' cash flowsit is less likely that their cash flows will become riskier all of a sudden and in such a short period of time. On the other hand, market microstructure effects can be reflected in prices and, hence, in betas, soon after an event such as the introduction of SSFs contracts for stocks.

Equation (1) is, therefore, applied separately to each of the SSFslisted and non-SSFs stocks for pre-SSFs and post-SSFs periods over three different sampling intervals (six months, 12 months, and two years) to determine the impact of SSFs trading in the short term, medium term, and longer term, respectively. The empirical results (not reported in this study) show that the $\beta_{3}$ coefficient is not statistically significant for the majority of 
SSFs-listed and non-SSFs stocks across all three sampling intervals. The $\beta_{1}$ coefficient can, therefore, be used to estimate if the systematic risk (beta coefficient) of SSFs stocks has changed in the post-SSFs trading period.

Table 1 gives the number and percentage of stocks for changes (significant increase, decrease, or no change) in the beta coefficient for SSFs and a sample of non-SSFs stocks for three different sampling intervals (sixmonth, one-year, and two-year periods). The table indicates no systematic pattern in the change (increase or decrease) in beta coefficients either for the SSFs or the sample of non-SSFs stocks in the post-futures period. For instance, in the case of the six-month interval, the beta coefficients for nine (19.6 percent) SSFs stocks and another 11 (23.9 percent) SSFs-listed stocks exhibit a significant increase and decrease, respectively, after futures trading begins for these stocks. More than 56 percent of SSFs stocks undergo no significant change in the systematic risk coefficient for the same period.

Table 1: Percentage of stocks with beta changes for SSFs-listed and non-SSFs stocks (post- and pre-futures periods for different sampling periods)

\begin{tabular}{lccc}
\hline SSFs-listed stocks & $\mathbf{6}$ month' time & 1 year's time & 2 years' time \\
\hline Increases in beta & $9(19.57 \%)$ & $9(19.57 \%)$ & $5(10.86 \%)$ \\
Decreases in beta & $11(23.89 \%)$ & $18(39.30 \%)$ & $25(54.38 \%)$ \\
No changes in beta & $26(69.23 \%)$ & $19(41.13 \%)$ & $16(34.78 \%)$ \\
Total & $46(100 \%)$ & $46(100 \%)$ & $46(100 \%)$ \\
\hline Non-SSFs stocks & $\mathbf{6}$ month' time & $\mathbf{1}$ year's time & $\mathbf{2}$ years' time \\
Increases & $5(5.6 \%)$ & $18(20.45 \%)$ & $13(14.778 \%)$ \\
z-statistic & {$[0.681]$} & {$[-0.0652]$} & {$[-0.7993]$} \\
Decreases & $9(10.22 \%)$ & $26(29.54 \%)$ & $37(42.04 \%)$ \\
z-statistic & {$[1.1599]$} & {$[0.597]$} & {$[-0.0774]$} \\
No changes & $74(84.10 \%)$ & $44(50 \%)$ & $38(43.18 \%)$ \\
\hline Test statistic & & & \\
z-statistic & {$[-1.243]$} & {$[-0.5741]$} & {$[-0.5704]$} \\
Total & $46(100 \%)$ & $46(100 \%)$ & $46(100 \%)$ \\
\hline
\end{tabular}

Note: The words 'increases' and 'decreases' represent the number and percentage of stocks with a significant increase or decrease in the post-futures period, while 'no change' represents the number of stocks with no significant change in beta estimates. The detailed results for each stock are not reported here and can be provided on request.

Source: Authors' calculations. 
For the sample of non-SSFs stocks for same period (six-month interval), five (5.6 percent) stocks and another nine (10.2 percent) non-SSFs stocks exhibit a significant increase and decrease, respectively. However, the majority of non-SSFs stocks undergo no significant change in their beta coefficients. For longer sample intervals (one- and two-year periods), there is a slight increase in the number of stocks (both SSFs-listed and control group stocks) whose beta estimate falls in the post-futures period.

To test whether the SSFs-listed stocks' beta changes are different from those of the control group stocks across each of the three sampling intervals, we calculate the z-statistics for each (reported in the last panel of the table). The test statistic indicates no significant difference in the proportion of stocks with significant changes (increase or decrease) between SSFs-listed and non-SSFs stocks for each of the three sampling intervals. These results indicate that SSFs trading might not have an impact on the betas of the SSFs-listed stocks either in the short or long run.

\section{Discussion and Conclusion}

We have examined changes in the beta coefficients (systematic risk) of the underlying stocks post-SSFs listings in Pakistan's market by employing a model that accounts for nonsynchronous trading and varying market conditions such as bull and bear markets. Unlike the results of some earlier studies on the US market, our empirical evidence tends to support a decline in systematic risk for the majority of the underlying stocks subsequent to futures listings.

Nevertheless, as pointed out by McKenzie, Brailsford, and Faff (2001), this reduction in beta could also be attributed to market-wide movements. We therefore consider the results for a control group, and in line with our results for SSFs stocks, find empirical evidence of a decrease in systematic risk for many of the non-SSFs listed stocks. This shows that changes in beta estimates for SSFs-listed stocks might not necessarily be induced by the introduction of SSFs trading for those stocks but could be attributed to other market-wide or industry-related changes that have affected the overall market. These results for Pakistan's SSFs market are consistent with the findings of Galloway and Miller (1997) who attribute apparent changes in the risk of index stocks to market-wide changes that are not associated with the initiation of index futures.

Several plausible reasons could explain these different results for Pakistan's market. One is the market's lack of program trading activities- 
the main reason emphasized by Martin and Senchack (1989) and Damodaran (1990) as a cause of an increase in systematic risk of the index constituent stocks. Another possible reason is the use of a methodology that allows us to capture bull and bear market effects on stock betas, which previous studies have not accounted for; the changes in beta in these studies could be attributed to bear and bull market conditions rather than to index futures trading. Additionally, market microstructure differences between more developed markets and emerging markets such as Pakistan are a possible reason for the differences in our findings. Nevertheless, our study leaves scope for further research in this context, but does show that SSFs trading does not necessarily have any impact on the underlying stock's co-movement with the market. 


\section{References}

Antoniou, A., Holmes, P., \& Priestley, R. (1998). The effects of stock index futures trading on stock index volatility: An analysis of the asymmetric response of volatility to news. Journal of Futures Markets, 18(2), 151-166.

Antoniou, A., \& Holmes, P. (1995). Futures trading, information, and spot price volatility: Evidence for the FTSE-100 stock index futures contract using GARCH. Journal of Banking and Finance, 19(1), 117129.

Black, F. (1976). Studies of stock price volatility changes. In Proceedings of the 1976 Meetings of the Business and Economic Statistics Section, American Statistical Association (pp. 177-181).

Bollerslev, T. (1986). Generalized autoregressive conditional heteroskedasticity. Journal of Econometrics, 31, 307-327.

Brealey, R. A. (2000, February). Stock prices, stock indexes and index funds. Bank of England Quarterly Bulletin, 61-80.

Chan, H. W. H., \& Howard, P. F. (2002). Additions to and deletions from an open-ended market index: Evidence from the Australian All Ordinaries. Australian Journal of Management, 27, 45-74.

Chong, C. W., Ahmad, M. I., \& Abdullah, M. Y. (1999). Performance of GARCH models in forecasting stock market volatility. Journal of Forecasting, 18(5), 333-342.

Conrad, J. (1989). The price effect of option introduction. Journal of Finance, 44(2), 487-498.

Damodaran, A. (1990). Index futures and stock market volatility. Review of Futures Markets, 9(2), 442-457.

Dawson, P. (2007). A new use for single stock futures. Journal of Derivatives and Hedge Funds, 13(1), 59-66.

Dhillon, U., \& Johnson, H. (1991). Changes in the Standard \& Poor's 500 list. Journal of Business, 64(1), 298-317. 
Dimson, E. (1979). Risk measurement when shares are subject to infrequent trading. Journal of Financial Economics, 7, 197-226.

Elliott, W., \& Warr, R. (2003). Price pressure on the NYSE and the NASDAQ: Evidence from S\&P 500 index changes. Financial Management, 32(3), 85-99.

Engel, R. F. (1982). Autoregressive conditional heteroskedasticity with estimates of the variance of the United Kingdom inflation. Econometrica, 50(4), 987-1007.

Engel, R. F., \& Ng, V. K. (1993). Measuring and testing the impact of news on volatility. Journal of Finance, 48(5), 1749-1778.

Epps, T. W. (1979). Co-movements in stock prices in the very short run. Journal of the American Statistical Association, 74, 291-298.

Fabozzi, F. J., \& Francis, J. C. (1977). Stability tests for alphas and betas over bull and bear market conditions. Journal of Finance, 32(4), 1093-1099.

Fabozzi, F. J., \& Francis, J. C. (1979). Mutual fund systematic risk for bull and bear markets: An empirical examination. Journal of Finance, 34(5), 1243-1250.

Ferson, W., \& Schadt, R. (1996). Measuring fund strategy and performance in changing economic conditions. Journal of Finance, $51,425-462$.

Francis, J. C., \& Fabozzi, F. J. (1979). The effects of changing macroeconomic conditions on the parameters of the single index market model. Journal of Financial and Quantitative Analysis, 14(2), 351-360.

Frimpong, J. M. (2010). An empirical analysis of stock pricing, systematic risks and returns on the Ghana Stock Exchange. The Business Review, Cambridge, 16(2), 186-195.

Galloway, T. M., \& Miller, J. M. (1997). Index futures trading and stock return volatility: Evidence from the introduction of MidCap 400 index futures. The Financial Review, 32(4), 845-876. 
Glosten, L. R., Jagannathan, R., \& Runkle, D. (1993). On the relation between the expected value and the volatility of the normal excess return on stocks. Journal of Finance, 48, 1779-1801.

Harris, L., \& Gurel, E. (1986). Price and volume effects associated with changes in the S\&P 500 list: New evidence for the existence of price pressures. Journal of Finance, 41(4), 815-829.

Hayashi, T., \& Yoshida, N. (2005). On covariance estimation of nonsynchronously observed diffusion processes. Bernoulli: Official Journal of the Bernoulli Society for Mathematics, Statistics, and Probability, 11(2), 359-379.

Howton, S. W., \& Peterson, D. R. (1998). An examination of crosssectional realized stock returns using a varying-risk beta model. The Financial Review, 33, 199-212.

Iqbal, J., \& Brooks, R. (2007). A test of CAPM on the Karachi Stock Exchange. International Journal of Business, 12(4), 429-444.

Jagannathan, R., \& Wang, Z. (1996).The conditional CAPM and the crosssection of expected returns. Journal of Finance, 51(1), 3-53.

Kan, A. C. N., \& Tang, G. Y. N. (1999). The impact of index futures trading on the betas of the underlying constituent stocks: The case of Hong Kong. Journal of International Financial Markets, Institutions and Money, 9(1), 97-114.

Kerl, A. G., \& Walter, A. (2006). Market responses to buy recommendations issued by German personal finance magazines: Effects of information, pricepressure, and company characteristics (Working paper). Tuebingen, Germany: University of Tuebingen, Department of Banking.

Khan, S. U. (2006). Role of the futures market on volatility and price discovery of the spot market: Evidence from Pakistan's stock market. Lahore Journal of Economics, 11(2), 107-121.

Khan, S. U., \& Hijazi, S. T. (2009). Single stock futures trading and stock price volatility: Empirical analysis. Pakistan Development Review, 48(4, Pt. II), 553-563.

Martin, J. D., \& Senchack, A. J. (1989). Program trading and systematic stock price behavior. Financial Analysts Journal, 45(3), 61-67. 
Martin, J. D., \& Senchack, A. J. (1991). Index futures, program trading, and the covariability of the major market index stocks. Journal of Futures Markets, 11(1), 95-111.

McKenzie, M. D., Brailsford, T. J., \& Faff, R. F. (2001). New insight into the impact of the introduction of futures trading on stock price volatility. Journal of Futures Markets, 21(3), 237-255.

Nelson, D. B. (1991). Conditional heteroskedasticity in asset returns: A new approach. Econometrica, 59(2), 347-370.

Pericli, A., \& Koutmos, G. (1997). Index futures and options and stock market volatility. Journal of Futures Markets, 17(8), 957-974.

Rowe, T., \& Kim, J. (2010). Analyzing the relationship between systematic risk and financial variables in the casino industry. UNLV Gaming Research and Review Journal, 14(2), 47-58.

Shanken, J. (1990). Intertemporal asset pricing: An empirical investigation. Journal of Econometrics, 45, 99-120.

Shleifer, A. (1986). Do demand curves for stock slope down? Journal of Finance, 41(3), 579-590.

Sias, R. W., Titman, S., \& Starks, L. T. (2001). The price impact of institutional trading (Working paper). Washington State University and University of Texas at Austin.

Skinner, D. J. (1989). Options markets and stock return volatility. Journal of Financial Economics, 23, 61-78.

Trahan, E. A., \& Bolster, P. J. (1997, April). The impact of second-hand information on stock prices: Tests of the information, price pressure, and implicit claims hypotheses. Paper prepared for the Eastern Finance Association Meeting, Panama City, FL.

Vijh, A. M. (1994). S\&P-500 trading strategies and stock betas. Review of Financial Studies, 7(1), 215-251.

Vipul. (2008). Mispricing, volume and volatility and open interest: Evidence from Indian futures market. Journal of Emerging Market Finance, 7(3), 263-292. 
Yip, Y.-Y., \& Lai, M.-M. (2009). Impact of warrant listings on its underlying stocks: The Malaysian evidence. Academy of Accounting and Financial Studies Journal, 13(3), 107-133.

Zakoian, J.-M. (1990). Threshold heteroskedastic models (Mimeo). Paris, France: Center for Research in Economics and Statistics 
Annex

\section{Specifications of SSF contracts traded on the Karachi Stock Exchange}

\begin{tabular}{|c|c|}
\hline Period of contract & 1 calendar month \\
\hline $\begin{array}{l}\text { Expiration date/last } \\
\text { trading day }\end{array}$ & $\begin{array}{l}\text { Last Friday of the calendar month; if the last Friday } \\
\text { is not a trading day, the immediate preceding } \\
\text { trading day. }\end{array}$ \\
\hline Final settlement & $\begin{array}{l}\text { Physical delivery of underlying shares on the basis } \\
\text { of } \mathrm{T}+2 \text {, falling immediately after the close of } \\
\text { contract. }\end{array}$ \\
\hline Initial margin & $50 \%$ cash of the total value of the contract ${ }^{10}$ \\
\hline Settlement day & $\begin{array}{l}\text { Wednesday following the last Friday of the } \\
\text { calendar month }\end{array}$ \\
\hline Settlement method & Physical delivery of the underlying shares \\
\hline Overlapping period & $\begin{array}{l}\text { None. Contract for different months can trade at the } \\
\text { same time. }\end{array}$ \\
\hline \multirow[t]{2}{*}{ Contract size } & Larger than or equal to that of a marketable lot \\
\hline & In the underlying share in ready market \\
\hline Opening of contract & $\begin{array}{l}\text { At least two days before the close of the old contract } \\
\text { period. }\end{array}$ \\
\hline \multirow[t]{2}{*}{ Regular trading hours } & Monday-Thursday: 0945-1415 \\
\hline & Friday: $0930-1200$ and $1430-1600$ \\
\hline Corporate events & $\begin{array}{l}\text { SSFs contracts adjusted to reflect changes to } \\
\text { underlying stocks }\end{array}$ \\
\hline Quotations/tick size & PKR 0.05 per share \\
\hline Contract size & 500 shares \\
\hline Contract multiplier & $\begin{array}{l}500 \text { shares, subject to changes when adjustments are } \\
\text { made with respect to corporate events. }\end{array}$ \\
\hline & Contract value $=$ futures price $x$ contract multiplier \\
\hline Position limits & $\begin{array}{l}\text { Individual broker or client-wise position limit is } 1 \% \\
\text { of the free float of a scrip }\end{array}$ \\
\hline
\end{tabular}

Source: Adapted from the Karachi Stock Exchange's "Regulations governing deliverable futures contracts $2004^{\prime \prime}$.

${ }^{10}$ In the new rules, amended in 2010, the initial margin has been increased to 100 percent cash or bank guarantee. 